Acta Crystallographica Section C

Crystal Structure

Communications

ISSN 0108-2701

\section{Hydrogen bonding in substituted nitroanilines: isolated nets in 1,3-diamino-4-nitrobenzene and continuously interwoven nets in 3,5-dinitroaniline}

\author{
Christopher Glidewell, ${ }^{\mathrm{a} *}$ Debbie Cannon, ${ }^{\mathrm{b}}$ Antonio \\ Quesada, ${ }^{b}+$ John N. Low, ${ }^{\text {}}$ ¥ Susan A. McWilliam, ${ }^{c}$ \\ Janet M. S. Skakle ${ }^{\mathrm{C}}$ and James L. Wardell ${ }^{\mathrm{C}}$
}

${ }^{a}$ School of Chemistry, University of St Andrews, St Andrews, Fife KY16 9ST, Scotland, 'bepartment of Electronic Engineering and Physics, University of Dundee, Nethergate, Dundee DD1 4HN, Scotland, and ${ }^{\mathrm{c}}$ Department of Chemistry, University of Aberdeen, Meston Walk, Old Aberdeen AB24 3UE, Scotland

Correspondence e-mail: cg@st-andrews.ac.uk

Received 8 January 2001

Accepted 25 January 2001

Molecules of 1,3-diamino-4-nitrobenzene, $\mathrm{C}_{6} \mathrm{H}_{7} \mathrm{~N}_{3} \mathrm{O}_{2}$, are linked by $\mathrm{N}-\mathrm{H} \cdots \mathrm{O}$ hydrogen bonds $[\mathrm{N} \cdots \mathrm{O} 2.964$ (2) and 3.021 (2) $\AA$; $\mathrm{N}-\mathrm{H} \cdots \mathrm{O} 155$ and $149^{\circ}$ ] into $(4,4)$ nets. In 3,5dinitroaniline, $\mathrm{C}_{6} \mathrm{H}_{5} \mathrm{~N}_{3} \mathrm{O}_{4}$, where $Z^{\prime}=2$, the molecules are linked by three $\mathrm{N}-\mathrm{H} \cdots \mathrm{O}$ hydrogen bonds [N...O 3.344 (2)3.433 (2) $\AA$ and $\mathrm{N}-\mathrm{H} \cdots \mathrm{O} 150-167^{\circ}$ ] into deeply puckered nets, each of which is interwoven with its two immediate neighbours.

\section{Comment}

Mononitroanilines and their simple C-methylated derivatives can form hydrogen-bonded supramolecular structures in one, two, or three dimensions. Thus, 2-nitroaniline (Dhaneshwar et al., 1978) and 4-methyl-2-nitroaniline (Cannon et al., 2001) both form simple chains, 3-nitroaniline (Ploug-Sørensen \& Andersen, 1986) and 4-nitroaniline (Tonogaki et al., 1993) both form sheets, while 2-methyl-4-nitroaniline forms a threedimensional framework (Ferguson et al., 2001). Although the methyl groups play no direct role in the hydrogen bonding, nonetheless they can have a major influence on the overall supramolecular structure in some instances. Thus, while 3-nitroaniline forms sheets, its 4-methyl analogue (Cannon et al., 2001) forms a mixture of ladders and simple chains; similarly the supramolecular structure of 4-nitroaniline is twodimensional, while that of its 2-methyl analogue is threedimensional.

† On leave from Departamento de Química Inorgánica y Orgánica, Universidad de Jaén, 23071 Jaén, Spain.

$\ddagger$ Postal address: Department of Electronic Engineering \& Physics, University of Dundee, Nethergate, Dundee DD1 4HN, Scotland.
Notional replacement of a methyl group by either a second amino group or by a second nitro group, which thus introduces an excess either of hydrogen-bond donors or of hydrogenbond acceptors, may be expected to have a significant influence of the resulting supramolecular structures. We report here the structures of two such examples, 1,3-diamino-4nitrobenzene, (I), which has an excess of donors, and 3,5dinitroaniline, (II), which has an excess of acceptors.<smiles>Nc1ccc([N+](=O)[O-])c(N)c1</smiles>

(I)<smiles></smiles>

( $\mathrm{I} a)$<smiles></smiles>

(III $a)$<smiles>Nc1cc([N+](=O)[O-])cc([N+](=O)[O-])c1</smiles>

(II)<smiles>NC1=CC(=[NH2+])C(=[N+]([O-])[O-])C=C1</smiles>

(Ib)<smiles></smiles>

(III $b)$
In compound (I) (Fig. 1), there is an intramolecular $\mathrm{N}-$ $\mathrm{H}$.. O hydrogen bond, forming an $S(6)$ motif, as observed in 2-nitroaniline itself and in its $\mathrm{C}$-methyl derivatives. In addition, each molecule acts as a double donor of intermolecular $\mathrm{N}-\mathrm{H} \cdots \mathrm{O}$ hydrogen bonds (Table 2), utilizing for this purpose just one $\mathrm{N}-\mathrm{H}$ bond in each amino group, and as a double acceptor of such bonds; the molecules are thereby linked into planar $(4,4)$ nets (Batten \& Robson, 1998) parallel to $(010)$. These nets are most simply analysed in terms of chain formation along the [101] and [101] directions. Atom N3 acts as a hydrogen-bond donor, via $\mathrm{H} 31$, to $\mathrm{O} 2$ at $\left(\frac{1}{2}+x, \frac{3}{2}-y\right.$,

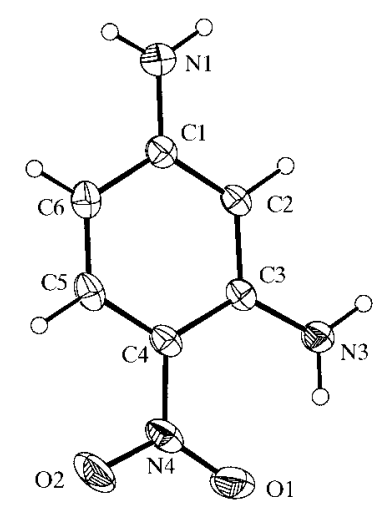

Figure 1

The asymmetric unit of (I) showing the atom-labelling scheme. Displacement ellipsoids are drawn at the $30 \%$ probability level. 
$\frac{1}{2}+z$ ), while $\mathrm{N} 3$ at $\left(\frac{1}{2}+x, \frac{3}{2}-y, \frac{1}{2}+z\right)$ in turn acts as donor to $\mathrm{O} 2$ at $(1+x, y, 1+z)$, so forming a $C(6)$ chain running parallel to the [101] direction and generated by the glide plane at $y=$ 0.75. This chain is enhanced by a rather weak $\mathrm{C}-\mathrm{H} \cdots \mathrm{O}$ hydrogen bond to the same acceptor atom (Table 2). At the same time, atom $\mathrm{N} 1$ acts as donor, via $\mathrm{H} 12$, to $\mathrm{O} 1$ at $\left(-\frac{1}{2}+x\right.$, $\left.\frac{3}{2}-y, \frac{1}{2}+z\right)$ and in this way a $C(8)$ chain running parallel to [101] is generated by the same glide plane. The combination of the [101] and [101] chains of $\mathrm{N}-\mathrm{H} \cdots \mathrm{O}$ hydrogen-bonded molecules generates the $(4,4)$ net built from a single type of $R_{4}^{4}$ (24) ring (Fig. 2). The non-H atoms of this net lie in the domain $0.51<y<0.99$, and there is a second similar net passing through the unit cell, generated by the glide plane at $y=0.25$ and lying in the domain $0.01<y<0.49$. There are no hydrogen bonds or $\pi-\pi$-stacking interactions between adjacent nets, so that the supramolecular aggregation is strictly two-dimensional.

The supramolecular structure of compound (I) may be compared with those of both 2-nitroaniline and 4-nitroaniline, as the molecular constitution of (I) shares features with both these nitroanilines. The intramolecular $S(6)$ motif is common to both (I) and 2-nitroaniline, as is the formation of $C(6)$ chains. On the other hand, the formation of a $(4,4)$ net is observed both in (I) and in 4-nitroaniline, but the surprising feature in (I) is that the net formation utilizes only one $\mathrm{N}-\mathrm{H}$ bond per amino group, while one of the $\mathrm{N}-\mathrm{H}$ bonds, $\mathrm{N} 1-$ H11, does not participate at all in the hydrogen bonding (Table 2).

Compound (II) crystallizes with $Z^{\prime}=2$ in $P 2_{1} / n$ : the different hydrogen-bonding characteristics of the two independent molecules (Table 4) are sufficient to rule out the possibility of any additional symmetry. Within the selected asymmetric unit (Fig. 3), N11 in molecule 1 acts as hydrogen-

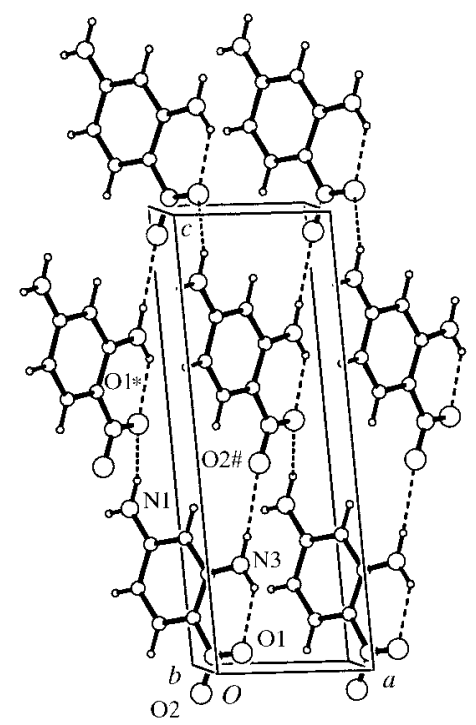

Figure 2

Part of the crystal structure of (I) showing the formation of a (010) net built from $R_{4}^{4}(24)$ rings. For the sake of clarity, $\mathrm{H}$ atoms bonded to C atoms have been omitted. Atoms marked with an asterisk (*) or hash (\#) are at the symmetry positions $\left(-\frac{1}{2}+x, \frac{3}{2}-y, \frac{1}{2}+z\right)$ and $\left(\frac{1}{2}+x, \frac{3}{2}-y, \frac{1}{2}+z\right)$ respectively.

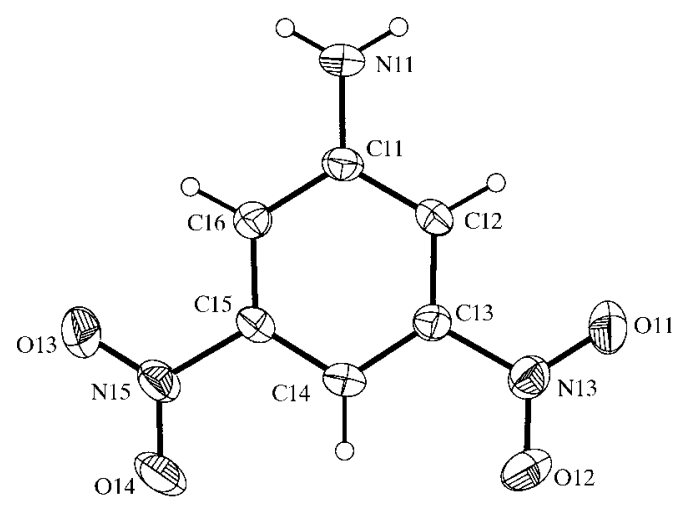

(a)

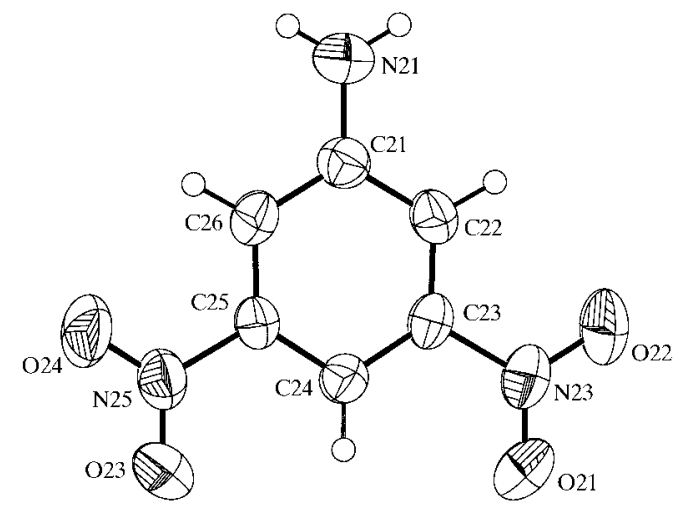

(b)

Figure 3

The two independent molecules in (II) showing the atom-labelling schemes for $(a)$ molecule 1 and $(b)$ molecule 2. Displacement ellipsoids are drawn at the $30 \%$ probability level.

bond donor, via $\mathrm{H} 1 A$, to $\mathrm{O} 23$ in molecule 2, and each of these two-molecule units is linked to four others: N11 and N21 each acts as a single donor, via $\mathrm{H} 1 B$ and $\mathrm{H} 2 B$, respectively, while $\mathrm{O} 12$ and $\mathrm{O} 21$ are each single acceptors. The primary hydrogen-bonded structure is a sheet, most easily analysed in terms of the linking of spiral chains. Atom N11 at $(x, y, z)$ acts as donor, via $\mathrm{H} 1 B$, to $\mathrm{O} 21$ at $\left(\frac{1}{2}-x,-\frac{1}{2}+y, \frac{1}{2}-z\right)$, while N11 at $\left(\frac{1}{2}-x,-\frac{1}{2}+y, \frac{1}{2}-z\right)$ in turn acts as donor to O21 at $(x$, $-1+y, z)$; this hydrogen bond thus produces a $C_{2}^{2}(10)$ chain running parallel to the [010] direction and generated by the $2_{1}$ screw axis along $\left(\frac{1}{4}, y, \frac{1}{4}\right)$. The molecules of types 1 and 2 alternate along this chain, acting as double donors and double acceptors, respectively. These chains are linked into continuous sheets by a third $\mathrm{N}-\mathrm{H}$. . O hydrogen bond. Atom N21 at $(x, y, z)$ acts as donor, via $\mathrm{H} 2 B$, to $\mathrm{O} 12$ at $(1+x, 1+y, z)$, so producing by translation a $C_{2}^{2}(14)$ chain parallel to the [110] direction; the molecules of types 1 and 2 again alternate along this chain, but within this chain each acts as a single donor and a single acceptor. The combination of the [010] and [110] chains generates a deeply puckered sheet parallel to (001) built from $R_{10}^{10}(58)$ rings (Fig. 4). There are two such sheets running through each unit cell, related to one another by the action of the centres of inversion. The original sheet lies in the domain $-0.25<z<0.75$ and its symmetry-generated 

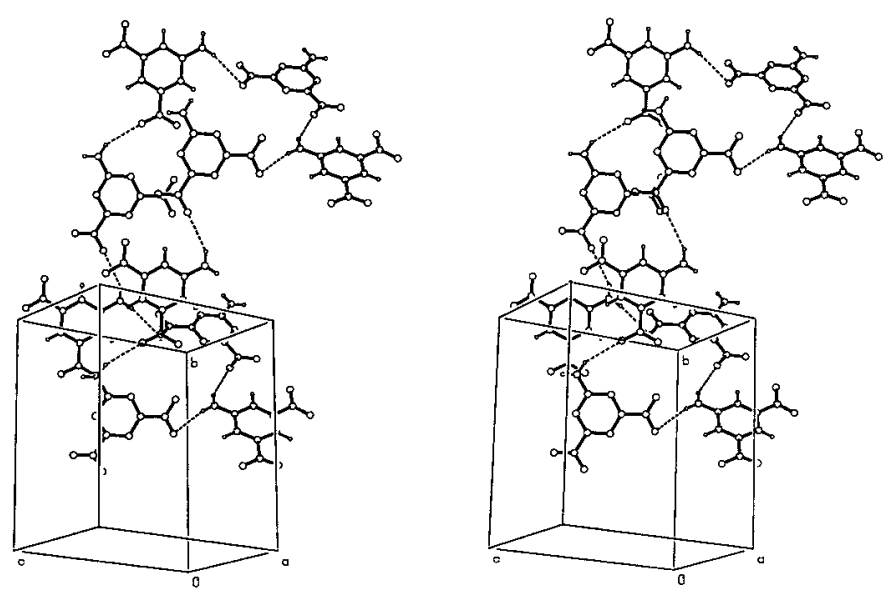

Figure 4

Stereoview of part of the crystal structure of (I) showing one of the $R_{10}^{10}(58)$ rings forming the (001) nets. For the sake of clarity, $\mathrm{H}$ atoms bonded to $\mathrm{C}$ atoms have been omitted.

companion lies in the domain $0.25<z<1.25$. Because of the puckered nature of these sheets, each sheet is interwoven with its two immediate neighbours, so producing a continuous three-dimensional network of interwoven sheets.

Isomeric with compound (I) are 2,4-dinitroaniline [Cambridge Structural Database (CSD; Allen \& Kennard, 1993) refcode QQQFNG02 (Prasad et al., 1982)] and 2,6-dinitroaniline (CUZDEG; Parkanyi \& Kalman, 1984). The molecules in QQQFNG02 contain the intramolecular $S(6)$ motif characteristic of 2-nitroanilines and, in addition, they are linked by paired $\mathrm{N}-\mathrm{H} \cdots \mathrm{O}$ and $\mathrm{C}-\mathrm{H} \cdots \mathrm{O}$ hydrogen bonds into chains of fused alternating $S(6)$ and $R_{2}^{2}(8)$ rings (Fig. 5). In CUZDEG, the amino group forms $S(6)$ motifs with both nitro groups and a combination of $\mathrm{N}-\mathrm{H} \cdots \mathrm{O}$ and $\mathrm{C}-\mathrm{H} \cdots \mathrm{O}$ hydrogen bonds links the molecules into a chain of fused

\section{Figure 5}

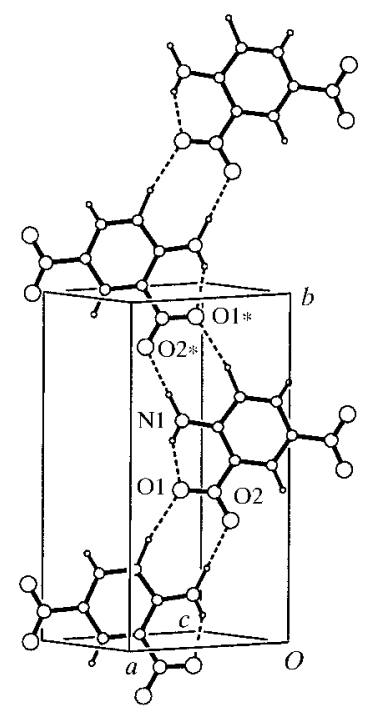

Part of the crystal structure of 2,4-dinitroaniline (QQQFNG02) showing the formation of a [010] chain of alternating $S(6)$ and $R_{2}^{2}(10)$ rings. Atoms marked with an asterisk $(*)$ are at the symmetry position $\left(1-x, \frac{1}{2}+y\right.$, $\left.\frac{1}{2}-z\right)$

$R_{4}^{4}(13)$ rings from which the paired $S(6)$ rings are pendent (Fig. 6).

The two $\mathrm{C}-\mathrm{NH}_{2}$ distances in compound (I) are very different (Table 1), but the longer of these is very similar to the two independent $\mathrm{C}-\mathrm{NH}_{2}$ distances in compound (II). On the other hand, the $\mathrm{C}-\mathrm{NO}_{2}$ distance in (I) is $c a 0.10 \AA$ shorter than the corresponding distances in (II), which are closely grouped about their mean value of 1.469 (2) A. These observations, together with the marked $\mathrm{C}-\mathrm{C}$ bond fixation in (I), indicate that in (I) there is an important contribution from the quinonoid form ( $\mathrm{I} a$ ), but essentially none from the alternative form $(\mathrm{I} b)$. It is thus interesting to note that in QQQFNG02, the pattern of $\mathrm{C}-\mathrm{N}$ and $\mathrm{C}-\mathrm{C}$ bond lengths points clearly to form (III $a$ ) as an important contributor to the exclusion of form (III $b$ ). In compound (II), the 1,3,5-substitution pattern effectively precludes the development of such forms, although there is a clear distinction between the lengths of the eight $\mathrm{C}-$ $\mathrm{C}$ bonds adjacent to an $\mathrm{NO}_{2}$ group [range 1.365(2)1.380 (2) $\AA$, mean 1.376 (2) $\AA$ ] and the four such bonds remote from an $\mathrm{NO}_{2}$ group [range $1.389(2)-1.396(2) \AA$, mean $1.392(2) \AA]$.

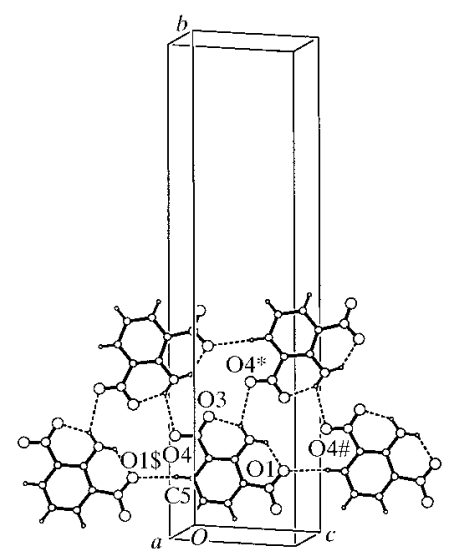

Figure 6

Part of the crystal structure of 2,6-dinitroaniline (CUZDEG) showing the

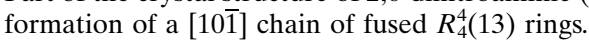

\section{Experimental}

Commercial samples of compounds (I) and (II) were purified by chromatography on silica gel with $\mathrm{CHCl}_{3}$ as eluant. Crystals suitable for single-crystal $\mathrm{X}$-ray diffraction were grown by slow evaporation of solutions in ethanol.

\section{Compound (I)}

\section{Crystal data}

$\mathrm{C}_{6} \mathrm{H}_{7} \mathrm{~N}_{3} \mathrm{O}_{2}$

$M_{r}=153.15$

Monoclinic, $P 2_{1} / n$

$a=4.4772(3) \AA$

$b=11.1379(7) \AA$

$c=13.1891(9) \AA$

$\beta=94.7480(10)^{\circ}$

$V=655.44(8) \AA^{3}$

$Z=4$

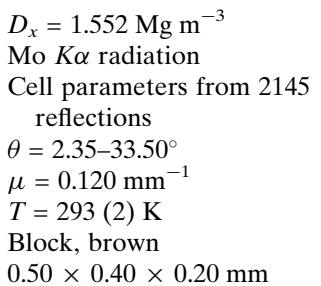

$D_{x}=1.552 \mathrm{Mg} \mathrm{m}^{-3}$

Mo $K \alpha$ radiation

reflections

$\theta=2.35-33.50^{\circ}$

$T=293$ (2) K

$0.50 \times 0.40 \times 0.20 \mathrm{~mm}$ 


\section{Data collection}

Bruker SMART 1000 CCD diffractometer

$\varphi$ and $\omega$ scans

Absorption correction: multi-scan

(SADABS; Bruker, 1997)

$T_{\min }=0.940, T_{\mathrm{max}}=0.976$

6928 measured reflections

2480 independent reflections

\section{Refinement}

Refinement on $F^{2}$

$R\left[F^{2}>2 \sigma\left(F^{2}\right)\right]=0.059$

$w R\left(F^{2}\right)=0.193$

$S=1.037$

2480 reflections

100 parameters

Table 1

Selected bond lengths $(\AA)$ for (I).

\begin{tabular}{llll}
\hline $\mathrm{C} 1-\mathrm{C} 2$ & $1.3875(19)$ & $\mathrm{C} 1-\mathrm{N} 1$ & $1.3204(17)$ \\
$\mathrm{C} 2-\mathrm{C} 3$ & $1.3548(18)$ & $\mathrm{C} 3-\mathrm{N} 3$ & $1.3592(17)$ \\
$\mathrm{C} 3-\mathrm{C} 4$ & $1.3738(17)$ & $\mathrm{C} 4-\mathrm{N} 4$ & $1.3628(18)$ \\
$\mathrm{C} 4-\mathrm{C} 5$ & $1.402(2)$ & $\mathrm{N} 4-\mathrm{O} 1$ & $1.2524(19)$ \\
$\mathrm{C} 5-\mathrm{C} 6$ & $1.320(2)$ & $\mathrm{N} 4-\mathrm{O} 2$ & $1.1983(16)$ \\
$\mathrm{C} 6-\mathrm{C} 1$ & $1.3679(19)$ & & \\
\hline
\end{tabular}

\section{Table 2}

Hydrogen-bonding geometry $\left(\AA{ }^{\circ}\right)$ for $(\mathrm{I})$.

\begin{tabular}{lllll}
\hline$D-\mathrm{H} \cdots A$ & $D-\mathrm{H}$ & $\mathrm{H} \cdots A$ & $D \cdots A$ & $D-\mathrm{H} \cdots A$ \\
\hline $\mathrm{N} 1-\mathrm{H} 12 \cdots \mathrm{O} 1^{\mathrm{i}}$ & 0.86 & 2.25 & $3.021(2)$ & 149 \\
$\mathrm{~N} 3-\mathrm{H} 31 \cdots \mathrm{O} 2^{\mathrm{ii}}$ & 0.86 & 2.16 & $2.964(2)$ & 155 \\
$\mathrm{C} 2-\mathrm{H} 2 \cdots \mathrm{O} 2^{\mathrm{ii}}$ & 0.93 & 2.55 & $3.321(2)$ & 140
\end{tabular}

Symmetry codes: (i) $x-\frac{1}{2}, \frac{3}{2}-y, \frac{1}{2}+z$; (ii) $\frac{1}{2}+x, \frac{3}{2}-y, \frac{1}{2}+z$.

\section{Compound (II)}

\section{Crystal data}

$$
\begin{aligned}
& \mathrm{C}_{6} \mathrm{H}_{5} \mathrm{~N}_{3} \mathrm{O}_{4} \\
& M_{r}=183.13 \\
& \text { Monoclinic, } P 2_{1} / n \\
& a=8.5377(6) \AA \\
& b=14.0119(9) \AA \\
& c=12.7071(8) \AA \\
& \beta=90.899(2)^{\circ} \\
& V=1519.96(17) \AA^{3} \\
& Z=8
\end{aligned}
$$

\section{Data collection}

Bruker SMART 1000 CCD diffractometer

$\varphi$ and $\omega$ scans

Absorption correction: multi-scan

(SADABS; Bruker, 1997)

$T_{\min }=0.921, T_{\max }=0.986$

15462 measured reflections

5510 independent reflections

\section{Refinement}

Refinement on $F^{2}$

$R\left[F^{2}>2 \sigma\left(F^{2}\right)\right]=0.046$

$w R\left(F^{2}\right)=0.133$

$S=0.825$

5510 reflections

235 parameters
1530 reflections with $I>2 \sigma(I)$

$R_{\text {int }}=0.042$

$\theta_{\text {max }}=33.50^{\circ}$

$h=-6 \rightarrow 6$

$k=-8 \rightarrow 16$

$l=-20 \rightarrow 18$

Intensity decay: negligible

$\mathrm{H}$-atom parameters constrained

$w=1 /\left[\sigma^{2}\left(F_{o}^{2}\right)+(0.1104 P)^{2}\right]$

where $P=\left(F_{o}{ }^{2}+2 F_{c}{ }^{2}\right) / 3$

$(\Delta / \sigma)_{\max }=0.005$

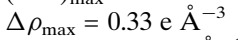

$\Delta \rho_{\min }=-0.26 \mathrm{e}^{-3}$

Table 3

Selected bond lengths (Å) for (II).

\begin{tabular}{llll}
\hline $\mathrm{C} 11-\mathrm{C} 12$ & $1.395(2)$ & $\mathrm{C} 21-\mathrm{C} 22$ & $1.396(2)$ \\
$\mathrm{C} 12-\mathrm{C} 13$ & $1.374(2)$ & $\mathrm{C} 22-\mathrm{C} 23$ & $1.365(2)$ \\
$\mathrm{C} 13-\mathrm{C} 14$ & $1.3704(19)$ & $\mathrm{C} 23-\mathrm{C} 24$ & $1.373(2)$ \\
$\mathrm{C} 14-\mathrm{C} 15$ & $1.379(2)$ & $\mathrm{C} 24-\mathrm{C} 25$ & $1.380(2)$ \\
$\mathrm{C} 15-\mathrm{C} 16$ & $1.367(2)$ & $\mathrm{C} 25-\mathrm{C} 26$ & $1.372(2)$ \\
$\mathrm{C} 16-\mathrm{C} 11$ & $1.389(2)$ & $\mathrm{C} 26-\mathrm{C} 21$ & $1.389(2)$ \\
$\mathrm{C} 11-\mathrm{N} 11$ & $1.3607(19)$ & $\mathrm{C} 21-\mathrm{N} 21$ & $1.364(2)$ \\
$\mathrm{C} 13-\mathrm{N} 13$ & $1.467(2)$ & $\mathrm{C} 23-\mathrm{N} 23$ & $1.4732(19)$ \\
$\mathrm{N} 13-\mathrm{O} 11$ & $1.2196(18)$ & $\mathrm{N} 23-\mathrm{O} 21$ & $1.2088(18)$ \\
$\mathrm{N} 13-\mathrm{O} 12$ & $1.2132(18)$ & $\mathrm{N} 23-\mathrm{O} 22$ & $1.2181(19)$ \\
$\mathrm{C} 15-\mathrm{N} 15$ & $1.4683(19)$ & $\mathrm{C} 25-\mathrm{N} 25$ & $1.468(2)$ \\
$\mathrm{N} 15-\mathrm{O} 13$ & $1.2188(19)$ & $\mathrm{N} 25-\mathrm{O} 23$ & $1.2013(18)$ \\
$\mathrm{N} 15-\mathrm{O} 14$ & $1.2174(18)$ & $\mathrm{N} 25-\mathrm{O} 24$ & $1.2159(18)$ \\
\hline
\end{tabular}

Table 4

Hydrogen-bonding geometry $\left(\AA,^{\circ}\right)$ for (II).

\begin{tabular}{lllll}
\hline$D-\mathrm{H} \cdots A$ & $D-\mathrm{H}$ & $\mathrm{H} \cdots A$ & $D \cdots A$ & $D-\mathrm{H} \cdots A$ \\
\hline $\mathrm{N} 11-\mathrm{H} 1 A \cdots \mathrm{O} 23$ & 0.86 & 2.59 & $3.377(2)$ & 152 \\
$\mathrm{~N} 11-\mathrm{H} 1 B \cdots \mathrm{O} 21^{\mathrm{i}}$ & 0.86 & 2.59 & $3.433(2)$ & 167 \\
$\mathrm{~N} 21-\mathrm{H} 2 B \cdots \mathrm{O} 12^{\mathrm{ii}}$ & 0.86 & 2.57 & $3.344(2)$ & 150 \\
$\mathrm{C} 22-\mathrm{H} 22 \cdots \mathrm{O} 12^{\mathrm{ii}}$ & 0.93 & 2.48 & $3.315(2)$ & 149 \\
$\mathrm{C} 26-\mathrm{H} 26 \cdots \mathrm{O} 11^{\mathrm{iii}}$ & 0.93 & 2.49 & $3.292(2)$ & 145 \\
\hline
\end{tabular}

Symmetry codes: (i) $\frac{1}{2}-x, y-\frac{1}{2}, \frac{1}{2}-z$; (ii) $1+x, 1+y, z$; (iii) $\frac{1}{2}+x, \frac{1}{2}-y, \frac{1}{2}+z$.

Compounds (I) and (II) both crystallized in the monoclinic system; space group $P 2_{1} / n$ was assumed from the systematic absences in each case. $\mathrm{H}$ atoms were treated as riding atoms with $\mathrm{C}-\mathrm{H}$ distances of $0.93 \AA$ and $\mathrm{N}-\mathrm{H}$ distances of $0.86 \AA$.

For both compounds, data collection: XPREP (Bruker, 1997); cell refinement: $X P R E P$; data reduction: $X P R E P$; $\operatorname{program}(\mathrm{s})$ used to solve structure: SHELXS97 (Sheldrick, 1997); program(s) used to refine structure: SHELXL97 (Sheldrick, 1997); molecular graphics: PLATON (Spek, 2000); software used to prepare material for publication: SHELXL97 and WordPerfect macro PRPKAPPA (Ferguson, 1999).

X-ray data were collected at Aberdeen using a Bruker SMART 1000 CCD diffractometer. The authors thank Dr W. T. A. Harrison for all his help and advice.

\author{
$D_{x}=1.601 \mathrm{Mg} \mathrm{m}^{-3}$ \\ Mo $K \alpha$ radiation \\ Cell parameters from 2507 \\ reflections \\ $\theta=2.85-26.18^{\circ}$ \\ $\mu=0.137 \mathrm{~mm}^{-1}$ \\ $T=293$ (2) K \\ Prism, yellow \\ $0.60 \times 0.30 \times 0.10 \mathrm{~mm}$
}

2160 reflections with $I>2 \sigma(I)$
$R_{\text {int }}=0.051$
$\theta_{\max }=32.64^{\circ}$
$h=-12 \rightarrow 9$
$k=-21 \rightarrow 20$
$l=-18 \rightarrow 19$
Intensity decay: negligible

$\mathrm{H}$-atom parameters constrained $w=1 /\left[\sigma^{2}\left(F_{o}^{2}\right)+(0.0622 P)^{2}\right]$ where $P=\left(F_{o}^{2}+2 F_{c}^{2}\right) / 3$

$(\Delta / \sigma)_{\max }<0.001$

$\Delta \rho_{\max }=0.27{\mathrm{e} \AA^{-3}}^{-3}$

$\Delta \rho_{\min }=-0.24 \mathrm{e}^{-3}$
Supplementary data for this paper are available from the IUCr electronic archives (Reference: SK1454). Services for accessing these data are described at the back of the journal.

\section{References}

Allen, F. H. \& Kennard, O. (1993). Chem. Des. Autom. News, 8, 1, 31-37. Batten, S. R. \& Robson, R. (1998). Angew. Chem. Int. Ed. Engl. 37, 1460-1494. Bruker (1997). XPREP. Bruker AXS Inc., Madison, Wisconsin, USA.

Cannon, D., Glidewell, C., Low, J. N., Quesada, A. \& Wardell, J. L. (2001). Acta Cryst. C57, 216-221.

Dhaneshwar, N. N., Tavale, S. S. \& Pant, L. M. (1978). Acta Cryst. B34, 25072509.

Ferguson, G. (1999). PRPKAPPA. University of Guelph, Canada.

Ferguson, G., Glidewell, C., Low, J. N., Skakle, J. M. S. \& Wardell, J. L. (2001). Acta Cryst. C57, 315-316.

Parkanyi, L. \& Kalman, A. (1984). J. Mol. Struct. 125, 315-320.

Ploug-Sørensen, G. \& Andersen, E. K. (1986). Acta Cryst. C42, 1813-1815.

Prasad, L., Gabe, E. J. \& Le Page, Y. (1982). Acta Cryst. B38, 674-675.

Sheldrick, G. M. (1997). SHELXS97 and SHELXL97. University of Göttingen, Germany.

Spek, A. L. (2000). PLATON. University of Utrecht, The Netherlands. Tonogaki, M., Kawata, T., Ohba, S., Iwata, Y. \& Shibuya, I. (1993). Acta Cryst. B49, 1031-1039. 